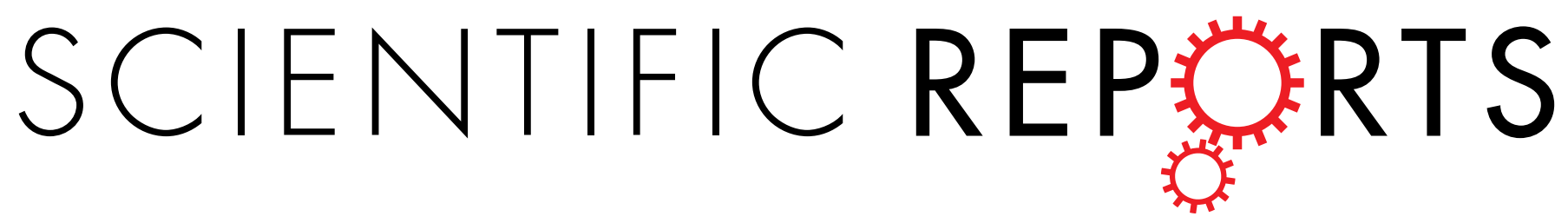

\title{
Corrigendum: Regulation of synaptic plasticity and cognition by SUMO in normal physiology and Alzheimer's disease
}

Linda Lee, Elena Dale, Agnes Staniszewski, Hong Zhang, Faisal Saeed, Mikako Sakurai, Mauro Fa', Ian Orozco, Francesco Michelassi, Nsikan Akpan, Helaina Lehrer \& Ottavio Arancio

Scientific Reports 4:7190; doi: 10.1038/srep07190; published online 2 December 2014; updated 07 July 2015

The original version of this Article contained a typographical error in the spelling of the author Helaina Lehrer which was incorrectly given as Helena Lehrer. This has now been corrected in the PDF and HTML versions of the Article. 